\title{
Effect of lead exposure from electronic waste on haemoglobin synthesis in children
}

\author{
Hongwu Wang ${ }^{1,2} \cdot$ Peng Huang ${ }^{1} \cdot$ Ruibiao Zhang ${ }^{7} \cdot$ Xueyong Feng $^{2} \cdot$ Qiulin Tang $^{2} \cdot$ Sixi Liu $^{1} \cdot$ Feiqiu Wen ${ }^{1} \cdot$ Li Zeng $^{6}$. \\ Yufeng Liu ${ }^{5}$ Tianyou Wang ${ }^{4} \cdot$ Lian Ma ${ }^{1,2,3}$
}

Received: 15 August 2020 / Accepted: 20 November 2020 / Published online: 20 January 2021

(c) The Author(s) 2021

\begin{abstract}
Background Primitive electronic waste (e-waste) recycling is ongoing in Guiyu, so toxic heavy metals may continue to threaten the health of children in the area.

Objective This study primarily aimed to evaluate the effect of e-waste exposure on haemoglobin (Hb) synthesis in preschool children.

Methods Medical examinations were conducted with the permission of children's guardians and the approval of the Ethics Committee of the Medical College of Shantou University. This study recruited 224 children (aged 3-6 years, exposed group) who lived in Guiyu and 204 children (aged 3-6 years, control group) who lived in a town free of e-waste pollution. Blood levels of lead, $\mathrm{Hb}$, ferritin, folate and vitamin $\mathrm{B}_{12}$ were tested in all children. Furthermore, all children were assessed for thalassemia, and their parents were asked to fill in questionnaires.

Results There were no significant differences in the level of ferritin, folate, or vitamin $\mathrm{B}_{12}$ between the exposed and control groups $(P>0.05)$. No children were identified as having thalassemia in all study participants. Blood lead level (BLL) and the risk of children with $\mathrm{BLL} \geq 10 \mu \mathrm{g} / \mathrm{dL}$ in the exposed group were significantly higher than those in the control group (all $P<0.01$ ). Three subgroups of each group were created according to BLL (Group A: $<5.0 \mu \mathrm{g} / \mathrm{dL}$; Group B: 5.0-9.9 $\mu \mathrm{g} / \mathrm{dL}$; Group $\mathrm{C}: \geq 10.0 \mu \mathrm{g} / \mathrm{dL})$. Hb level decreased with elevated BLL in the exposed group $(P=0.03)$, but not in the control group $(P=0.14)$. Hb levels in group $B$ and group $C$ were also significantly lower in the exposed group than in the control group (Group B: $122.6 \pm 9.5 \mathrm{~g} / \mathrm{L}$ versus $125.8 \pm 8.2 \mathrm{~g} / \mathrm{L}, P=0.01$; Group C: $120.3 \pm 7.3 \mathrm{~g} / \mathrm{L}$ versus $123.6 \pm 8.3 \mathrm{~g} / \mathrm{L}, P=0.03$ ). In addition, the prevalence of anaemia associated with BLLs above $10 \mu \mathrm{g} / \mathrm{dL}$ and between 5.0 and $9.9 \mu \mathrm{g} / \mathrm{dL}$ were both significantly higher in the exposed group than in the control group ( $4.0 \%$ vs. $0.5 \%, 5.4 \%$ vs. $1.5 \%$, respectively, both $P<0.05)$. Conclusion Lead exposure more significantly inhibits $\mathrm{Hb}$ synthesis in children who live in e-waste dismantling areas than in those who live in non-e-waste dismantling areas. Other toxins released from e-waste may also contribute to the inhibition of $\mathrm{Hb}$ synthesis and may lead to anaemia in local children. Further investigations are needed to provide evidence for the development of relevant protective measures.
\end{abstract}

Keywords E-waste $\cdot$ Blood lead $\cdot$ Haemoglobin $\cdot$ Anaemia $\cdot$ Preschool children

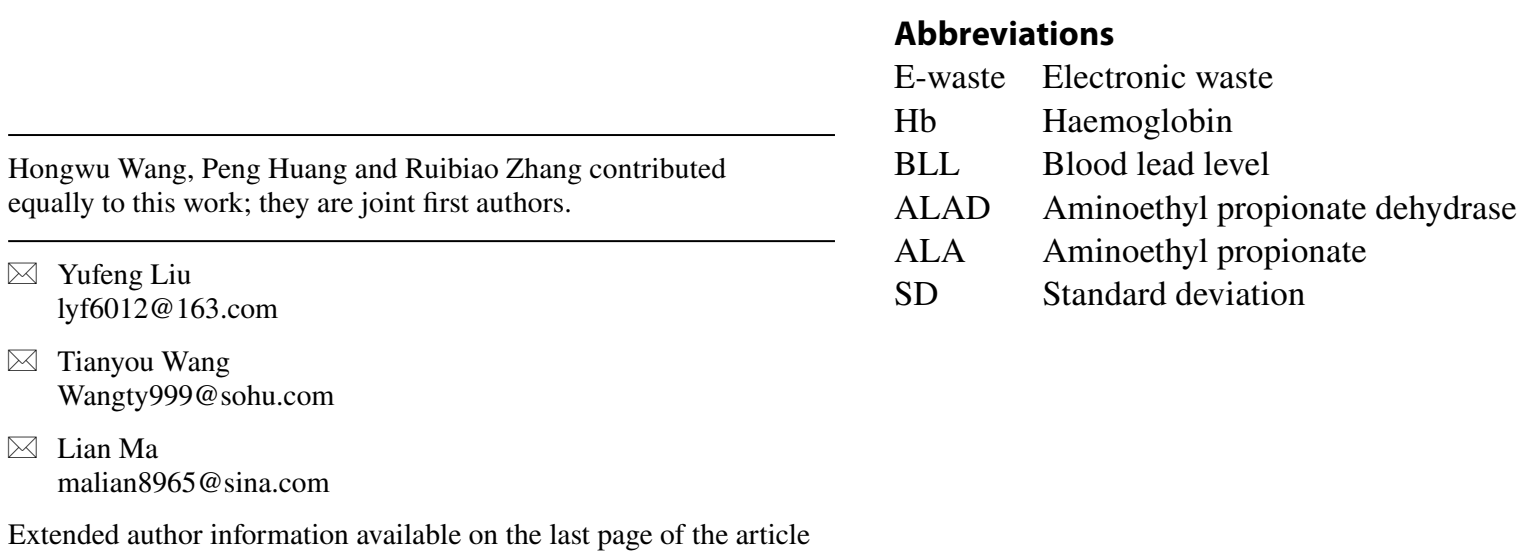




\section{Introduction}

Childhood is a period of rapid growth and development of all the organs and systems of the body. In addition to genetic factors that may lead to disorders of the blood system, the lack of various haematopoietic substances, such as dietary nutrients, proteins, and vitamins, can seriously impact it. Haemoglobin synthesis requires the coordinated production of haeme and globin. Haeme is the prosthetic group that mediates reversible binding of oxygen by haemoglobin. Globin is the protein that surrounds and protects the haeme molecule. Haeme or globin synthesis disorders can cause haemoglobin synthesis to decline. Moreover, the toxic effects of harmful environmental substances may inhibit the synthesis of normal haemoglobin $(\mathrm{Hb})$ in children and even lead to anaemia. Anaemia not only affects children's physical and mental development but also makes children susceptible to some diseases that can pose a great threat to their health and even endanger their lives. According to a survey of anaemia in Guangdong, China, the prevalence of anaemia among children aged 3-6 years in underdeveloped rural areas in Guangdong is $10.73 \%$ (Xiao-feng et al. 2015). There are many causes of anaemia in children. The common causes are iron deficiency, nutritional megaloblastic and thalassemia.

Except for the most common causes of anaemia in children, lead is recognized as one of the main environmental toxins that has the ability to inhibit $\mathrm{Hb}$ synthesis. The mechanism for this inhibition is as follows: lead can inhibit aminoethyl propionate dehydrase (ALAD), which hinders the conversion of aminoethyl propionate (ALA) into protoporphyrin and reduces $\mathrm{Hb}$ synthesis. In addition, lead can inhibit iron-chelating enzymes and prevent protoporphyrin and divalent iron from synthesizing haeme. Under the influence of lead, the conformation of $\mathrm{Hb}$ changes, and the sensitivity of $\mathrm{Hb}$ to proteolytic enzymes increases, thus accelerating its decomposition (Ortega et al. 2013; Kayaalti et al. 2016).

Guiyu, Guangdong Province, known as the "World Electronic Waste Disposal Station," has a greater than 20 -year history of e-waste recycling. Every year, this town disposes of millions of tons of e-waste, electrical appliances, and plastics from various countries, such as the United States, Germany, Japan, and Korea. Local workers use simple and rudimentary disassembly methods to handle waste, such as combustion and acid washing. Without any further treatment, acid washing wastewater that has heavy metal concentrations seriously exceeding the standards is then discharged into nearby streams, which are often used for irrigation or even drunk directly by local residents. The leftover waste is incinerated. It is difficult to completely break down e-waste; hence, toxic substances, such as lead, cadmium, polychlorinated biphenyls, carbon chloride and brominated flame retardants, inevitably persist in the environment. Huo et al. reported that the soil lead and cadmium levels in Guiyu were 2.32 and 4.34 times, while the ratios for dust sample were 4.10 and 3.18 times higher than a non-e-waste area (Yekeen et al. 2016). In comparison to the reservoir outside of Guiyu, Wang et al. found that the sediments of Lianjiang and Nanyang River in Guiyu were more enriched with dissolved lead, cadmium, cuprum, nikel and zinc (Wang et al. 2009). Rice is a kind of major staple food in China and its quality is critical to human health. According to Fu et al., the mean level of lead in polished rice reached $0.69 \mathrm{mg} / \mathrm{kg}, 3.5$ fold higher than the maximum allowable concentration (MAC) $(0.20 \mathrm{mg} / \mathrm{kg})$ by the safety criteria for milled rice (NY5115-2002) (Fu et al. 2008). Long-term lead-containing food intake and environmental exposure to excessive lead can cause lead poisoning. Studies have shown that lead exposure in Guiyu had detrimental effects on the skeletal growth and neurobehavioural development of local children (Yang et al. 2013; Liu et al. 2011). Moreover, lead poisoning and other heavy metal poisoning are important factors leading to anaemia in children.

There are some reports related to lead exposure and anaemia. A study showed that blood lead and blood cadmium had an effect on $\mathrm{Hb}$ level. Blood lead and blood cadmium may interact with $\mathrm{Hb}$ (Chen et al. 2015). Kutllovci-Zogaj et al. used Spearman correlation analysis to analyse the relationship between BLL and $\mathrm{Hb}$ level in children in Mitrovica and found that there was a moderate correlation between BLL and Hb level (Kutllovci-Zogaj et al. 2014). However, previous studies did not exclude the influence of common nutritional and genetic factors in the impact of lead exposure on $\mathrm{Hb}$. It is well known that nutrition and some genetic factors have a great influence on the haemoglobin of preschool children. Hence, we conducted an investigation to address the issue of e-waste and its potential effects on $\mathrm{Hb}$ synthesis in children on the premise of excluding common nutritional and genetic factors.

\section{Methods}

\section{Study population}

This cross-sectional study included 222 children (boys: 126; girls: 96) aged 3-6 years from two kindergartens in Guiyu, an e-waste disposal area (exposed group). In addition, 204 children (boys: 112; girls: 92) aged 3-6 years were recruited from three kindergartens in the Haojiang District (mainly engaged in agriculture and fishery, approximately $50 \mathrm{~km}$ from Guiyu) (control group) in 2014. This district does not conduct e-waste disassembly operations. All participants 
fulfilled the inclusion criteria as determined by a questionnaire survey and laboratory tests: (1) they lived in the study area for at least 3 years; (2) they had no serious haematological system disease in the past, such as aplastic anaemia and leukaemia; (3) they had no history of taking iron, folic acid or vitamin $B_{12}$ in the past three months; and (4) thalassemia was excluded by $\mathrm{Hb}$ electrophoresis screening. Medical examinations were conducted with the permission of children and the written permission of the children's guardians and the approval of the Ethics Committee of the Medical College of Shantou University.

\section{Sample collection and biochemical measurements}

Care was taken to ensure that the venepuncture sites (routinely the back of the child's hand) were completely sterilized, and $5 \mathrm{ml}$ of venous blood was collected by a professional nurse. One millilitre of whole blood was immediately tested for $\mathrm{Hb}$ by the $\mathrm{Hb}$ cyanide ( $\mathrm{HiCN}$ ) method. One millilitre of whole blood was centrifuged at $5000 \mathrm{rpm}$ for $5 \mathrm{~min}$ for $\mathrm{Hb}$ electrophoresis screening. Serum was obtained from two millilitre of whole blood and centrifuged at $3000 \mathrm{rpm}$ for $15 \mathrm{~min}$ to determine ferritin, folic acid and vitamin $B_{12}$ levels. Hb level was measured using an automatic LH-780 haematology analyser (Beckmann, Germany). Hb electrophoresis was done using agarose gel zone electrophoresis (PN1210 electrophoresis apparatus, Sevilla, France). Ferritin, folic acid, and vitamin 12 levels were determined via chemiluminescence (Advia Centaur XP automatic immunoassay of Siemens, Germany). Because children in both areas did not get their blood drawn at the same time, to reduce the detection error, the remaining $1 \mathrm{ml}$ of blood was placed in a 2-ml vacuum blood vessel containing EDTA (40 U) anticoagulant, and each blood sample was stored at $-20^{\circ} \mathrm{C}$ to detect the BLL. The blood collection and sample management processes were carried out by professional staff, and all laboratory indicators adhered to standard reference materials.

\section{Measurement of BLLs}

Before analyses, $100 \mu \mathrm{L}$ of sampled blood was added to $900 \mu \mathrm{l}$ of $0.5 \%$ nitric acid. This was then vortexed and digested at room temperature for $10 \mathrm{~min}$. The resulting mixture was then used for the determination of lead levels.

Lead levels were determined using graphite furnace atomic absorption spectrophotometry (Zenit 650, Analytik Jena, Jena, Germany), which was done with an MPE60 autosampler (Analytik Jena, Jena, Germany) with an injection volume set at $20 \mu \mathrm{L}$. The main parameters used for the detection of lead levels were a wavelength of $283.3 \mathrm{~nm}$; a lamp current of $4.0 \mathrm{~mA}$; a slit width of $0.8 \mathrm{~nm}$; drying at $90{ }^{\circ} \mathrm{C}, 105{ }^{\circ} \mathrm{C}$, and $120^{\circ} \mathrm{C}$; ashing at $600^{\circ} \mathrm{C}$; and atomization at $1500{ }^{\circ} \mathrm{C}$. The standard calibration curve was plotted using the six working standard solutions, which were prepared from a stock lead standard solution diluted with nitric acid, to which a matrix modifier mixed with human blood was added. The linear correlation coefficient of the lead standard calibration curve was 0.9920 . The accuracy of the method was controlled by the use of recoveries between 96 and 108\% (Rui-biao et al. 2015).

\section{Diagnostic criteria}

According to the World Health Organization/UNICEF 2001 standard, anaemia is represented by $\mathrm{Hb}$ under $110 \mathrm{~g} / \mathrm{L}$ in those aged 6-59 months or a $\mathrm{Hb}$ less than $115 \mathrm{~g} / \mathrm{L}$ (level) in those aged between 6 and 11 years old (WHO 2011 ). Child BLLs were subdivided into low BLLs and high BLLs groups at $10.0 \mu \mathrm{g} / \mathrm{dL}$, in reference to the U. S. Center for Disease Control and Prevention (CDC) (Brown 2007). This is then amended to $5.0 \mu \mathrm{g} / \mathrm{dL}$ (Betts 2012). A ferritin level of $<16 \mu \mathrm{g} / \mathrm{L}$ indicates iron deficiency (Powers and Buchanan 2014). Beta-thalassemia occurs when $\mathrm{HBA}_{2}$ is $>3.5 \%$. Alpha poverty is diagnosed when $\mathrm{HBA}_{2}$ is $<2.5 \%$ or via abnormal HBH (HBBART) (Brancaleoni et al. 2016). A plasma folate level of $3 \mathrm{ng} / \mathrm{mL}$ indicates folate deficiency. A plasma Vitamin $B_{12}$ level of $200 \mathrm{pg} / \mathrm{mL}$ indicates folate deficiency (Finglas 2000).

\section{Questionnaire investigation}

The parents of the children examined were asked to complete a questionnaire regarding the socio-demographic characteristics of the children. The contents of the questionnaire mainly included the child's birthplace, health status, surroundings, family economic conditions, and parental education level. Three classifications of total family income were defined according to the following levels: $<1999$ Chinese yuan (333.2 US dollars, 1.0 US dollar $\approx 6.0$ Chinese yuan in 2014) per month equated to low income, 2000-4999 Chinese yuan (333.3-833.2 US dollars) per month equated to middle income, and 5000 Chinese yuan (833.3 US dollar) per month equated to high-income families.

\section{Statistical analysis}

Data entry and statistical analysis were performed using SPSS 15.0 (SPSS Inc., Chicago, IL, USA). Data distribution was tested for normality with the Kolmogorov-Smirnov test. $\mathrm{Hb}$ level was normally distributed, and BLL, folate, vitamin $B_{12}$ and general characteristics were skewed. Data are expressed as arithmetic mean \pm standard deviation (SD), median (25th-75th percentile), or number (percentage), depending on their distribution. Comparisons between two independent samples were performed using 
the $t$ test or Mann-Whitney $U$ test. Three subgroups were created according to BLL (Group A: $<5.0 \mu \mathrm{g} / \mathrm{dL}$; Group B: 5.0-9.9 $\mu \mathrm{g} / \mathrm{dL}$; Group C: $\geq 10.0 \mu \mathrm{g} / \mathrm{dL})$ and compared by using one-way ANOVA. Categorical data were compared using the $\chi^{2}$ test. The significance level was $P<0.05$.

\section{Results}

\section{General characteristics and nutritional status of children in the two towns}

The general characteristics (including age, sex, family economic condition and parental education level) and nutritional status (including ferritin, folate and vitamin $\mathrm{B}_{12}$ ) of the children in two towns are shown in Table 1. There was no significant difference in age, sex, family income, or parents' education level between the two study groups $(P>0.05)$. All children were excluded from thalassemia by $\mathrm{Hb}$ electrophoresis. There was no significant difference between groups in the level of ferritin, folic acid, or vitamin $\mathrm{B}_{12}$ in children with anaemia $(P>0.05)$.

Unit measurement: $1 \mathrm{mg} / \mathrm{L}=1000 \mu \mathrm{g} / \mathrm{L}(\mu \mathrm{g} / \mathrm{L}-$ microgram/litre); $1 \mathrm{mg} / \mathrm{mL}=1,000,000 \mathrm{ng} / \mathrm{mL}$ (ng/ml -nanogram/ millilitre); $0.001 \mathrm{ng} / \mathrm{ml}=1 \mathrm{pg} / \mathrm{mL}$ (picogram/millilitre).

\section{BLLs of children in the two towns}

There was a significant difference in BLL between the two groups. The average BLL in the exposed group was higher than in the control group $(P<0.01)$. The risk of children with BLLs above $10 \mu \mathrm{g} / \mathrm{dL}$ in the exposed group was significantly higher than that in the control group $(P<0.01)$, while no difference in the two groups with BLLs between 5.0 and $9.9 \mu \mathrm{g} / \mathrm{dL}(P>0.05)$. The data are shown in Table 2.

\section{Effects of different doses of BLLs on $\mathrm{Hb}$ concentration in the two towns}

The study participants were divided into three subgroups on the basis of their BLLs, including Group A (BLL $<5.0 \mu \mathrm{g}$ / $\mathrm{dL}$ ), Group B (BLL 5.0-9.9 $\mu \mathrm{g} / \mathrm{dL})$, and Group C (BLL $\geq 10.0 \mu \mathrm{g} / \mathrm{dL}$ ). Table 3 shows that there was no significant difference in the $\mathrm{Hb}$ levels between the three subgroups of the control group $(P>0.05)$. However, a significant difference was observed in the $\mathrm{Hb}$ levels between the three subgroups of the exposed group by one-way ANOVA, with a tendency for a decrease in $\mathrm{Hb}$ level with rising BLL in the exposed group $(P=0.03)$ but not in the control group $(P=0.14)$. In addition, the Hb levels of group B and group $\mathrm{C}$ were also significantly lower in the exposed group than in the control group (Group B: $122.6 \pm 9.5 \mathrm{~g} / \mathrm{L}$ versus

Table 1 Comparison of overall characteristics and nutritional status of the children in the two towns

\begin{tabular}{|c|c|c|c|}
\hline & Exposed group $(N=222)$ & Control group $(N=204)$ & $P$ value \\
\hline Age in months & $61.8 \pm 9.0$ & $60.0 \pm 10.2$ & $0.07^{\mathrm{a}}$ \\
\hline Boys, $n(\%)$ & $126(56.8)$ & $112(54.9)$ & $0.70^{\mathrm{c}}$ \\
\hline Family income more than 2000 yuan per month, $n(\%)$ & $136(61.3)$ & $128(62.7)$ & $0.29^{c}$ \\
\hline Fathers with an education level of senior high school and above, $n(\%)$ & $166(74.8)$ & $160(78.4)$ & $0.37^{\mathrm{c}}$ \\
\hline Mothers with an education level of senior high school and above, $n(\%)$ & $180(81.1)$ & $170(83.3)$ & $0.54^{\mathrm{c}}$ \\
\hline Ferritin, $\mu \mathrm{g} / \mathrm{L}$ & $49.9(35.1-68.4)$ & $49.7(36.1-66.2)$ & $0.87^{b}$ \\
\hline Folate, ng/mL & $7.3(5.4-10.0)$ & $8.8(6.8-11.2)$ & $0.98^{\mathrm{b}}$ \\
\hline Vitamin $\mathrm{B}_{12}, \mathrm{pg} / \mathrm{mL}$ & $720.0(577.0-851.3)$ & $645.0(491.0-824.0)$ & $0.06^{\mathrm{b}}$ \\
\hline
\end{tabular}

Values are arithmetic mean $\pm \mathrm{SD}$, median (25th-75th percentile) and number (percentage)

${ }^{\text {a }} P$ value calculated by $t$ test

${ }^{\mathrm{b}} P$ value calculated by the Mann-Whitney $U$ test

${ }^{\mathrm{c}} P$ value calculated using the $\chi^{2}$ test

Table 2 Comparison of the average BLLs and rate of high BLLs between groups

\begin{tabular}{|c|c|c|c|c|c|c|c|c|c|c|c|c|c|}
\hline & \multicolumn{5}{|c|}{ BLLs, $\mu \mathrm{g} / \mathrm{dL}$} & \multicolumn{4}{|c|}{ BLLs 5.0-9.9 $\mu \mathrm{g} / \mathrm{dL}$} & \multicolumn{4}{|c|}{ BLLs $\geq 10.0 \mu \mathrm{g} / \mathrm{dL}$} \\
\hline & $N$ & median & 25th-75th percentile & $Z$ value & $P$ value & $n$ & Rate (\%) & $\chi^{2}$ value & $P$ value & $n$ & Rate $(\%)$ & $\chi^{2}$ value & $P$ value \\
\hline Exposed group & 222 & 8.5 & $6.6-10.9$ & -8.71 & $0.00^{\mathrm{a}}$ & 115 & 51.8 & 0.41 & $0.52^{\mathrm{b}}$ & 74 & 33.3 & 19.99 & $0.00^{\mathrm{b}}$ \\
\hline Control group & 204 & 6.0 & $4.8-7.9$ & & & 112 & 54.9 & & & 30 & 14.7 & & \\
\hline
\end{tabular}

${ }^{\text {a }} P$ value calculated by the Mann-Whitney $U$ test

${ }^{\mathrm{b}} P$ value calculated using the $\chi^{2}$ test 
Table 3 Effects of BLL on $\mathrm{Hb}$ concentration in the two towns

\begin{tabular}{llllllll}
\hline BLLs & \multicolumn{2}{l}{ Exposed group $(N=222)$} & & Control group $(N=204)$ & $T$ value & $P$ value $^{\mathrm{a}}$ \\
\cline { 2 - 3 } & $n$ & $\mathrm{Hb}(\bar{x} \pm \mathrm{s}, \mathrm{g} / \mathrm{L})$ & & & $\mathrm{Hb}(\bar{x} \pm \mathrm{s}, \mathrm{g} / \mathrm{L})$ & & \\
\hline$<5.0 \mu \mathrm{g} / \mathrm{dL}$ (Group A) & 33 & $124.9 \pm 8.2$ & & 62 & $126.9 \pm 8.5$ & -1.14 & 0.26 \\
$5.0-9.9 \mu \mathrm{g} / \mathrm{dL}$ (Group B) & 115 & $122.6 \pm 9.5$ & & 112 & $125.8 \pm 8.2$ & -2.54 & 0.01 \\
$\geq 10.0 \mu \mathrm{g} / \mathrm{dL}$ (Group C) & 74 & $120.3 \pm 7.3$ & & 30 & $123.6 \pm 8.3$ & -2.26 & 0.03 \\
$F$ value & & 3.52 & & 1.98 & & \\
$P$ value $^{\mathrm{b}}$ & & 0.03 & & 0.14 & & \\
\hline
\end{tabular}

${ }^{\text {a }} P$ value calculated by $t$ test

${ }^{\mathrm{b}} P$ value calculated by one-way ANOVA
$125.8 \pm 8.2 \mathrm{~g} / \mathrm{L}, P=0.01$; Group $\mathrm{C}: 120.3 \pm 7.3 \mathrm{~g} / \mathrm{L}$ versus $123.6 \pm 8.3 \mathrm{~g} / \mathrm{L}, P=0.03)$.

\section{Comparison of influencing factors of anaemia among children in the two towns}

As shown in Table 4, the prevalence of anaemia associated with BLLs above $10 \mu \mathrm{g} / \mathrm{dL}$ and between 5.0 and $9.9 \mu \mathrm{g} / \mathrm{dL}$ were both significantly higher in the exposed group than in the control group $(4.0 \%$ vs. $0.5 \%, 5.4 \%$ vs. $1.5 \%$, respectively, both $P<0.05)$. There was no significant difference between the exposed group and the control group in the prevalence of anaemia associated with iron deficiency (2.3\% vs. $2.9 \%, P>0.05)$. Furthermore, the prevalence of anaemia in children with low BLLs $(<5.0 \mu \mathrm{g} / \mathrm{dL})$ and with non-iron deficiency was also no significant difference between the two groups ( $1.4 \%$ vs. $1.5 \%, P>0.05)$.

\section{Discussion}

Worldwide, the main reason for decreased $\mathrm{Hb}$ synthesis in children is iron deficiency (WHO 2001). Other causes include folic acid and/or vitamin $\mathrm{B}_{12}$ deficiency and thalassemia (Madu and Ughasoro 2017). To explore the effect of e-waste pollution on $\mathrm{Hb}$ synthesis in children, it is necessary to exclude these common nutritional and genetic factors. Out of this concern, normal levels of ferritin, folic acid, and vitamin $B_{12}$ were required for our study, and there was no significant discrepancy in these levels between groups $(P>0.05)$. There is a relatively high incidence of thalassemia in Guangdong Province, as one study found an incidence of approximately $8.53 \%$ (Xu et al. 2004). To exclude any effect of thalassemia, we confirmed that no children who participated in our study had thalassemia by $\mathrm{Hb}$ electrophoresis screening.

It was necessary to understand the general characteristics (including social demography and cultural information) and nutritional status of children in the two regions. Families with higher maternal education may have better economic resources or engage in behaviours protective of child health, such as iron supplementation. The results showed that there was no significant difference in age, sex, family income, or parents' education level distribution between the two study groups $(P>0.05)$. This means that families in both places were unlikely to have differences in the rate of insufficient dietary intake due to economic difficulties.

As shown in Table 2, the average BLL in the exposed group was higher than that in the control group $(P<0.01)$. In addition, the risk of children with BLLs above $10 \mu \mathrm{g} /$ $\mathrm{dL}$ in the exposed group was significantly higher than that in the control group $(P<0.01)$. These results indicate that e-waste pollution had an impact on BLL in the study population. Whether lead can inhibit Hb synthesis is closely related to the child's lead load level. Research by Chen and Kutllovci-Zogaj showed that blood lead could interfere with
Table 4 Analysis of influencing factors of anaemia ${ }^{a}$ in children in an e-waste dismantling area

\begin{tabular}{|c|c|c|c|c|c|c|}
\hline & \multicolumn{2}{|c|}{ Exposed group $(N=222)$} & \multicolumn{2}{|c|}{ Control group $(N=204)$} & \multirow[b]{2}{*}{$\chi^{2}$ value } & \multirow[b]{2}{*}{$P$ value } \\
\hline & Anaemia, $n$ & Anaemia, $\%$ & Anaemia,n & Anaemia, $\%$ & & \\
\hline BLLs $>10 \mu \mathrm{g} / \mathrm{dL}$ & 9 & 4.0 & 1 & 0.5 & 4.44 & 0.03 \\
\hline BLLs $5.0-9.9 \mu \mathrm{g} / \mathrm{dL}$ & 12 & 5.4 & 3 & 1.5 & 4.85 & 0.03 \\
\hline Iron deficiency ${ }^{\mathrm{b}}$ & 5 & 2.3 & 6 & 2.9 & 0.20 & 0.65 \\
\hline $\begin{array}{l}\text { BLLs }<5 \mu \mathrm{g} / \mathrm{dL} \text { and } \\
\text { non-iron deficiency }\end{array}$ & 3 & 1.4 & 3 & 1.5 & 0.00 & 1.00 \\
\hline
\end{tabular}

${ }^{\mathrm{a}}$ Haemoglobin $(\mathrm{Hb})<11.0 \mathrm{~g} / \mathrm{dL}$ for children between 6 and 59 months and $\mathrm{Hb}<11.5 \mathrm{~g} / \mathrm{dL}$ for children between 6 and 11 years old

${ }^{\mathrm{b}}$ Ferritin level $<16 \mathrm{ng} / \mathrm{mL}$ 
Hb synthesis (Chen et al. 2015; Kutllovci-Zogaj et al. 2014). The United States Centers for Disease Control (CDC) has recommended that BLL can be used for the assessment of the lead load in the body and the degree of lead poisoning. At present, a BLL of $20-40 \mu \mathrm{g} / \mathrm{dL}$ is considered the critical range at which normal $\mathrm{Hb}$ synthesis is affected. When the BLL is $40-60 \mu \mathrm{g} / \mathrm{dL}$ or $>60 \mu \mathrm{g} / \mathrm{dL}$, Hb synthesis will be inhibited, and there is an $18 \%$ to $40 \%$ probability of anaemia at the two former levels (Schwartz et al. 1990). In this study (Table 2), the majority of the children in both the exposed and the control groups had BLLs of less than $20 \mu \mathrm{g} / \mathrm{dL}$. This indicates that low blood lead concentrations may also inhibit $\mathrm{Hb}$ synthesis. According to the NHANES III survey in the United States, $\mathrm{Hb}$ synthesis can begin to be inhibited even at a BLL of 5.0-9.9 $\mu \mathrm{g} / \mathrm{dL}$ (Bernard and McGeehin 2003). Data suggested that lead-induced anaemia is mediated by the inhibition of $\mathrm{Hb}$ synthesis (Osterode et al. 1999).

This study showed that $\mathrm{Hb}$ levels in the exposed group decreased significantly with increasing blood lead load, but not in the control group (Table 3). Moreover, the prevalence of anaemia in children with high BLLs $(\geq 5.0 \mu \mathrm{g} /$ $\mathrm{dL}$ ) in the exposed group was significantly higher than that in the control group (Table 4). This indicated that lead exposure in Guiyu is different from that in the none-waste disposal area, and there may be coexisting factors that enhance lead blood toxicity. In addition to lead, e-waste contains more than 700 substances, $50 \%$ of which may endanger human health, such as cadmium, mercury, hexavalent chromium, polyethylene, polystyrene, brominated flame retardants, and surface coatings (Davis and Heart 2018). It has been reported that $58 \mathrm{~kg}$ of mercury, $24.6 \mathrm{~kg}$ of cadmium $340.5 \mathrm{~kg}$ of arsenic, and several other substances can be separated from 1 ton of randomly collected electronic cards (Jin-qiu et al. 2007). These toxic substances may interact with lead or cause lead to inhibit $\mathrm{Hb}$ more strongly than when acting alone, even in a mild elevated BLL (5.0-9.9 $\mu \mathrm{g} / \mathrm{dL})$. Our previous study in this investigation group showed that there was a negative correlation between blood cadmium and $\mathrm{Hb}$ level in children in Guiyu (Rui-biao et al. 2015), which is consistent with other findings that the $\mathrm{Hb}$ level in the high-cadmium group was lower than that in the low-cadmium group (Jie-dan et al. 2010). Other substances are contained in e-waste, such as aluminium and benzene derivatives, have also been reported to inhibit Hb synthesis (Lin et al. 2013; Ghosh et al. 2017; Snyder 2000). In terms of heavy metal only, the analysis of river water samples and river sediment collected in Guiyu showed that these had high contents of silver, chromium, mercury nickel, copper, lead, zinc and other heavy metals. Chromium, mercury nickel, copper, lead, zinc and other heavy metals have common target organs and molecular targets, such as affecting the haematopoietic system of bone marrow, which would lead to anaemia. There are usually interactions between metals due to their similar chemical properties (Coby et al. 2007). Therefore, further study of the effects of other heavy metals on anaemia in children is required.

Studies have shown that lead can occupy iron ion sites in the intestinal mucosa or haematological system, thus increasing the absorption or reducing the excretion of lead. Therefore, with the increase in lead load in children, iron content will correspondingly decrease, which can lead to an increase in the incidence of iron deficiency anaemia (Conrad et al. 1992; Bradman et al. 2001). Unexpectedly, there was no significant difference in the incidence of iron deficiency anaemia between the exposed group and the control group $(P=0.65)$. The possible reasons might be that few children had BLLs $>20 \mu \mathrm{g} / \mathrm{dL}$, and normal ferritin status does not necessarily indicate iron sufficiency because ferritin is an acute-phase reactant and may be elevated by infection or inflammatory disease (Caterina and Maria 2008). Thus, some iron-deficient children may have been misclassified as iron-replete on the basis of the ferritin level, which would bias the data.

However, the study also has limitations that may bias the results. First, our study corrected the factors that may affect hemoglobin synthesis, such as folic acid and $\mathrm{B}_{12}$. But there are many factors affecting anemia, such as vitamin A deficiency and zinc deficiency, which will affect the synthesis and metabolism of hemoglobin. Second, in this study, hemoglobin screening was used to exclude children with thalassemia, but it did not exclude some diseases that may also cause anemia such as chronic infections and kidney diseases. Third, our study did not measure erythropoietin, hepcidin, transferrin receptor, transferrin and other iron metabolism parameters. Finally, the sample size of the study subjects was small.

In conclusion, lead exposure (excluding the effects of common nutritional factors and thalassemia) more significantly inhibits $\mathrm{Hb}$ synthesis in children who live in e-waste dismantling areas than in those who live in non-e-waste dismantling areas. Other toxins released from e-waste may also contribute to the inhibition of $\mathrm{Hb}$ synthesis and may even lead to anaemia in local children. Further investigations are needed to expand the sample size and provide evidence for the development of relevant protective measures.

Acknowledgements This research was funded by grants from the National Natural Science Foundation of China (No. 81671525 and No. 81070478), the Ministry of Health's health industry research project of China (No. 201002006), Sanming Project of Medicine in Shenzhen (No. SZSM201512033) and the Science and Technology planning Project of Shantou (No. [2018]155-1).

Author contributions Data curation: RZ and PH; Formal analysis: HW; Methodology, LZ; Project administration: XF and QT; Supervision: YL, TW and LM; Writing - original draft: HW and RZ; Writing review and editing: SL and FW. 


\section{Compliance with ethical standards}

Conflict of interest The authors state that there are no conflicts of interest regarding the publication of this article and that there are no financial ties to disclose.

Ethical approval This study was approved by the Ethics Committee of the Medical College of Shantou University and performed in accordance with the ethical standards as laid down in the 1964 Declaration of Helsinki and its later amendments or comparable ethical standard.

Informed consent Consent for publication was obtained.

Open Access This article is licensed under a Creative Commons Attribution 4.0 International License, which permits use, sharing, adaptation, distribution and reproduction in any medium or format, as long as you give appropriate credit to the original author(s) and the source, provide a link to the Creative Commons licence, and indicate if changes were made. The images or other third party material in this article are included in the article's Creative Commons licence, unless indicated otherwise in a credit line to the material. If material is not included in the article's Creative Commons licence and your intended use is not permitted by statutory regulation or exceeds the permitted use, you will need to obtain permission directly from the copyright holder. To view a copy of this licence, visit http://creativecommons.org/licenses/by/4.0/.

\section{References}

Bernard SM, McGeehin MA (2003) Prevalence of blood lead levels $>5 \mathrm{ug} / \mathrm{dL}$ among US children 1-5 Years of age and socioeconomic and demographic factors associated with blood of lead levels $5-10 \mathrm{ug} / \mathrm{dL}$, third national health and nutrition examination survey, 1988-1994. Pediatrics 112:1308-1313

Betts KS (2012) CDC updates guidelines for children's lead exposure. Environ Health Perspect 120:a268

Bradman A, Eskenazi B, Sutton P (2001) Iron deficiency associated with higher blood lead in children living in contaminated environments. Environ Health Perspect 109:1079-1089

Brancaleoni V, Di Pierro E, Motta I, Cappellini MD (2016) Laboratory diagnosis of thalassemia. Int J Lab Hematol 38(Suppl 1):32-40

Brown MJ (2007) Interpreting and managing blood lead levels $<10$ microg/dL in children and reducing childhood exposures to lead: recommendations of CDC's advisory committee on childhood lead poisoning prevention. Morb Mortal Wkly Rep 56:1-16

Caterina B-P, Maria M (2008) Iron deficiency in infancy and childhood. Pediatr Ann 37:329-337

Chen X, Zhou H, Li X et al (2015) Effects of lead and cadmium coexposure on hemoglobin in a Chinese population. Environ Toxicol Pharmacol 39:758-763

Coby SC, Wong SC, Wu Nurdan S et al (2007) Trace metal contamination of sediments in an e-waste processing village in China. Environ Pollut 145:434-442

Conrad ME, Umbreit JN, Moore EG et al (1992) Rodning CR Newly identified iron-binding protein in human duodenal mucosa. Blood 79:244-247

Davis G, Heart S (2018) Electronic waste: the local government perspective in queensland, Australia. Resour Conserv Recycl 52:1031-1039

Finglas PM (2000) Dietary reference intakes for thiamin, riboflavin, niacin, vitamin B6, folate, vitamin B12, pantothenic acid, biotin, and choline. Trends Food Sci Technol 11:296-297

Fu J, Zhou Q, Liu J et al (2008) High levels of heavy metals in rice (Oryza sativa L.) from a typical e-waste recycling area in southeast China and its potential risk to human health. Chemosphere 71:1269-1275

Ghosh S, Mishra R, Biswas S et al (2017) $\alpha$-Lipoic acid mitigates arsenic-induced hematological abnormalities in adult male rats. Iran J Med Sci 42:242-250

Jie-dan L, Xia H, Jin-rong H et al (2010) Relationship between blood cadmium and red blood cell parameters in children aged 3-7 years in Guiyu Area of Guangdong Province. J Shantou Univ Med College 23:100-110 (In Chinese)

Jin-qiu Xu, Hong Ma, Jing-wei W et al (2007) The progress of disposal and recycling technologies of waste electrical and electronic equipment. J Shanghai Second Polytech Univ 24:263-270 (In Chinese)

Kayaalti Z, Sert S, Kaya-Akyüzlü D et al (2016) Association between delta-aminolevulinic acid dehydratase polymorphism and placental lead levels. Environ Toxicol Pharmacol 41:147-151

Kutllovci-Zogaj D, Krasniqi S, Elezaj I et al (2014) Correlation between blood lead level and hemoglobin level in mitrovica children. Med Arch 68:324-328

Lin CY, Hsiao WC, Huang CJ et al (2013) Heme oxygenase-1 induction by the ROS-JNK pathway plays a role in aluminum-induced anemia. J Inorg Biochem 128:221-228

Liu J, Xu X, Wu K et al (2011) Association between lead exposure from electronic waste recycling and child temperament alterations. Neurotoxicology 32:458-464

Madu AJ, Ughasoro MD (2017) Anaemia of chronic disease: an indepth review. Med Princ Pract 26:1-9

Ortega F, Counter SA, Buchanan LH et al (2013) Declining blood lead and zinc protoporphyrin levels in ecuadorian andean children. Clin Biochem 46:1233-1238

Osterode W, Barnas U, Geissler K (1999) Dose dependent reduction of erythroid progenitor cells and inappropriate erythropoietin response in exposure to lead: new aspects of anaemia induced by lead. Occup Environ Med 56:106-109

Powers JM, Buchanan GR (2014) Diagnosis and management of iron deficiency anemia. Hematol Oncol Clin North Am 28:729-745

Rui-biao Z, Xia H, Gu-yu Ho et al (2015) Attention-deficit/hyperactivity symptoms in preschool children from an E-waste recycling town: assessment by the parent report derived from DSM-IV. BMC Pediat 15:51. https://doi.org/10.1186/s12887-015-0368-x

Schwartz J, Landrigan PJ, Baker EL et al (1990) Lead-induced anemia: dose-response relationships and evidence for a threshold. Am J Public Health 80:165-168

Snyder R (2000) Overview of the toxicology of benzene. J Toxicol Environ Health 61:339-346

Wang HM, Yu YJ, Han M et al (2009) Estimated PBDE and PBB congeners in soil from an electronics waste disposal site. Bull Environ Contam Toxicol 83:789-793

WHO (2011) Haemoglobin concentrations for the diagnosis of anaemia and assessment of severity. Vitamin and Mineral Nutrition Information System. Geneva, World Health Organization. http:// www.who.int/vmnis/indicators/haemoglobin.pdf.

WHO, UNICEF, UNU (2001) Iron deficiency anaemia: assessment, prevention and control, a guide for programme managers. Geneva, World Health Organization. http://www.who.int/ nutrition/publications/micronutrients/anaemia_iron_deficiency/ WHO_NHD_01.3/en/index.html.

Xiao-feng Y, Zu-guo Q, Xiao-fang L (2015) Survey on anemia and the dietary behavior of the 3-6 years old children in underdeveloped rural areas in Guangdong. Chinese J Health Edu 9:827-829 (In Chinese)

Xu XM, Zhou YQ, Luo GX et al (2004) The prevalence and spectrum of alpha and beta thalassaemia in Guangdong Province: implications for the future health burden and population screening. J Clin Pathol 57:517-522 
Yang H, Huo X, Yekeen TA et al (2013) Effects of lead and cadmium exposure from electronic waste on child physical growth. Environ Sci Pollut Res Int 20:4441-4447

Yekeen TA, Xu XJ, Zhang YL, Huo X (2016) Assessment of health risk of trace metal pollution in surface soil and road dust from e-waste recycling area in China. Environ Sci Pollut Res 23:17511-17524
Publisher's Note Springer Nature remains neutral with regard to jurisdictional claims in published maps and institutional affiliations.

\section{Authors and Affiliations}

\section{Hongwu Wang ${ }^{1,2} \cdot$ Peng Huang ${ }^{1} \cdot$ Ruibiao Zhang $^{7} \cdot$ Xueyong Feng $^{2} \cdot$ Qiulin Tang $^{2} \cdot$ Sixi Liu $^{1} \cdot$ Feiqiu Wen ${ }^{1}$. Li Zeng ${ }^{6}$. Yufeng Liu ${ }^{5} \cdot$ Tianyou Wang ${ }^{4} \cdot$ Lian Ma ${ }^{1,2,3}$}

1 Department of Hematology and Oncology, Shenzhen Children's Hospital of China Medical University, Shenzhen 518038, China

2 Department of Pediatrics, The Second Affiliated Hospital of Shantou University Medical College, Shantou 515041, China

3 Shenzhen Public Service Platform of Molecular Medicine in Pediatric Hematology and Oncology, Shenzhen 518000, China

4 Beijing Children's Hospital, Beijing 100045, China
5 Children's Hospital of the First Affiliated Hospital of Zhengzhou University, Zhengzhou 450000, China

6 Department of Clinical Laboratory of the First Affiliated Hospital of Zhengzhou University, Zhengzhou 450000, China

7 Department of Pediatrics, Third People's Hospital of Huizhou, Affiliated Huizhou Hospital of Guangzhou Medical University, Guangdong 516002, China 